\title{
O CINEMA, A EDUCAÇÃO E A CONSTRUÇÃO DE UM IMAGINÁRIO SOCIAL CONTEMPORÂNEO
}

\author{
Maria da Conceição Francisca Pires* \\ Sergio LuIz PEREIRA DA SilvA**
}

\begin{abstract}
RESUMO: A partir das contribuições filosóficas sobre o cinema e sua interferência na construção de imaginários sociais coletivos, buscamos nesse artigo desenvolver uma reflexão sobre o uso didático do cinema. A partir da constatação da necessidade do desenvolvimento de uma análise visual crítica das imagens, discutimos as possibilidades existentes para a efetivação dessa mirada crítica e como esta pode contribuir de forma significativa para a promoção de uma ação pedagógica antenada com as questões referentes ao sujeito contemporâneo e suas subjetivações.
\end{abstract}

Palavras-chave: Educação. Cinema. Análise visual crítica. Imagens. Imaginário.

\section{Cinema, education AND THE CONSTRUCTION OF A CONTEMPORARY SOCIAL IMAGINARY}

\begin{abstract}
Based on the philosophical contributions on cinema and its interference in the construction of collective social imaginaries, in this paper we seek to develop a reflection on the didactic use of cinema. After noting the need to develop a critical visual analysis of images, we discuss the existing possibilities for the realization of this critical gaze and how it can contribute significantly to the promotion of a pedagogical action in tune with the questions regarding the contemporary subject and their subjectivation.
\end{abstract}

Key words: Education. Cinema. Critical visual analysis. Images. Imaginary.

Programa de Pós-Graduação em História da Universidade Federal do Estado do Rio de Janeiro (Unirio). Rio de Janeiro (RJ) - Brasil.

** Programa de Pós-Graduação em Memória Social da Universidade Federal do Estado do Rio de Janeiro (Unirio). Rio de Janeiro (RJ) - Brasil.

Contato com os autores:<conceicao.pires@uol.com.br> 


\title{
LE CINÉMA, L'ÉDUCATION ET LA CONSTRUCTION D'UN IMAGINAIRE SOCIAL CONTEMPORAIN
}

\begin{abstract}
RÉSUMÉ: En s'appuyant sur les contributions philosophiques sur le cinéma et aussi son ingérence dans la construction de l'imaginaire social collectif, dans le présent article, nous cherchons à développer une réflexion sur l'utilisation de la didactique du cinéma. Après avoir souligné la nécessité de développer une analyse critique des images visuelles, nous discutons les possibilités pour la réalisation de ce regard critique et comment il peut contribuer de manière significative à la promotion d'une action pédagogique liée aux questions concernantes au sujet contemporain et ses subjectivations.
\end{abstract}

Mots-clés: L'éducation. Le cinéma. L'analyse visuelle critique. Images. Imaginaire.

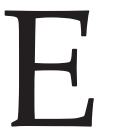

m As palavras e as coisas, ao discutir as questões que nortearam a episteme clássica, Foucault (2000) defende o argumento de que esta se fundamentava na representação, entendendo-se como representação a ordenação de signos verbais com a intenção de construir uma imagem do mundo. Esta configuração se modifica a partir do final do século XVIII, quando o conhecimento deixa de favorecer a representação e passa a privilegiar uma empiricidade. Nesse momento:

Ver consiste em deixar a experiência em sua maior opacidade corpórea; o solido, o obscuro, a densidade das coisas fechadas sobre si próprias tem poderes de verdade que não provém da luz, mas da lentidão do olhar que os percorre, contorna e, pouco a pouco, os penetra, conferindo-lhe apenas sua própria clareza. (FOUCAULT, 2000, p. 9-10)

Embora haja nesse momento a predominância de uma empiricidade, essa só se manifesta e ganha sentido através dos discursos que consistem em "determinados conhecimentos sobre o mundo que moldam a forma de o mundo ser compreendido e de as coisas serem feitas neste mundo [...]" (ROSE, 2001, p. 136-137).

As ideias de Foucault nos servem de introito para discutir a passagem de um período em que prevalece uma discursividade verbal, que se estendeu até meados do século XX, para o período contemporâneo onde há a inegável preeminência de uma discursividade visual que, no entanto, parece ainda não estar pronta, acabada, mas em construção.

As imagens, como textos, são formas de representar e encobrir o mundo. Servem para descrever as coisas e lhes dar sentido, suprimindo e integrando, desdobrando e restringindo a realidade ao mesmo tempo. O cinema, como artefato cultural que é, pode e deve ser explorado como forma de discurso que contribui para a construção de significados sociais. A junção das técnicas de filmagem e montagem com elenco e o processo de produção resultam num conjunto de significações que precisam ser partilhadas por quem o acessa, para que as imagens irradiadas possam produzir sentidos que, muitas vezes, tornam-se determinantes para suas vidas. 
Pensar a discursividade visual dos filmes é o ponto de partida para tomá-lo como uma face da produção do conhecimento. Atualmente, em tempos de globalização, acreditamos que as formas de aprender e de se desenvolver o conhecimento e o saber são diversas em virtude dos dispositivos didáticos e pedagógicos disponíveis com a sociedade em rede ou, como sociologicamente se convencionou chamar, a "sociedade da informação".

Dentro desse contexto informativo vimos surgir novas linguagens e novas formações culturais, nas quais os dispositivos informativos e os artefatos visuais atuam como objetos de circulação do conhecimento. A linguagem imagética do cinema cada vez mais tem contribuído na dinamização do processo de aprendizagem de crianças, jovens e adultos.

Nesse texto, quando identificamos o caráter discursivo do cinema estamos chamando atenção para um aspecto que transcende a sua condição de entretenimento e o seu papel denotativo. Interessa-nos o caráter atributivo que este possui quando constrói símbolos e sintomas que visam dar sentido à realidade vivida (FLUSSER, 1983; DUARTE, 2010). Atentamos, portanto, para o fato de que as imagens veiculadas pelo cinema, através do jogo de ludicidade, podem auxiliar de forma expressiva no aprimoramento da escola, sobretudo na relação com as temáticas culturais, sociais e históricas.

O gênero cinematográfico instrumentaliza a reprodução dos comportamentos culturais dentro de um conjunto de valores socioculturais e linguísticos, atuando como um artefato cultural de ordem simbólica que contribui para a consolidação do imaginário contemporâneo.

Na perspectiva de Walter Benjamin (1984) o cinema é um artefato cultural de dimensão coletiva que, através da reprodutibilidade técnica, facilita imageticamente o processo de alienação sociocultural. Este processo de reprodutibilidade técnica seria também responsável pela retirada da originalidade artística da obra cinematográfica, incidindo, consequentemente, na perda de sua aura e de sua autenticidade como obra de arte. Em suas palavras,

A autenticidade de uma coisa é a quintessência de tudo o que foi transmitido pela tradição, a partir de sua origem, desde sua duração material até o seu testemunho histórico. Como este depende da materialidade da obra, quando ela se esquiva do homem através da reprodução, também o testemunho se perde [...]. O conceito de aura permite resumir essas características: o que se atrofia na era da reprodutibilidade técnica da obra de arte é a sua aura. (BENJAMIN, 1984, p. 168)

Para Benjamin, o cinema é um dos agentes mais poderosos de massificação do mundo moderno. No processo coletivo de usufruto do cinema ocorre a dessubjetivação do indivíduo. Nulificado no todo, o indivíduo torna-se, por seu próprio desejo, 
massa, processo fundamental para a consolidação da indústria cultural, que se funda exatamente nesse processo de perda do indivíduo e de constituição da massa que partilha o interesse, o desfrute e o gozo pela mesma mercadoria.

Em suma, a multiplicação do cinema, através da reprodução técnica, o transforma em mercadoria, favorecendo, por conseguinte, o desenvolvimento do dispositivo de massificação ideológica, que tanto serviu aos regimes fascistas na reprodução do seu poder de controle e alienação por parte do Estado-nação. No período dos nacionalismos, a reprodutibilidade do cinema era mantenedora de uma conformação do imaginário político e de manutenção do status quo das classes sociais.

É por esse motivo que o cinema foi um instrumento utilizado por governos nacionalistas para produzir um sentido ideológico da história e como propaganda institucional. As formas de representações instrumentalizadas na linguagem cinematográfica facilitam o processo de alienação social, por contribuir para a formação do imaginário coletivo através dos processos de representações sociais presentes no discurso fílmico.

Nos dias atuais, essa reprodutibilidade técnica, facilitada pelos meios digitais, contribui para o processo de consumo de valores simbólicos, que se reproduzem e se modificam como produtos culturais de visualidade do status quo dos indivíduos na sociedade global. Na contemporaneidade, o cinema é um bem de consumo cultural que deixa pistas das mudanças comportamentais socioculturais globalizadas. Faz parte, portanto, de uma indústria cultural globalizada que uniformiza os valores de reconhecimento das diferenças e na qual os processos de interação do local com o global são parte de um mesmo contexto.

A facilidade com a qual o cinema atinge o imaginário social demonstra sua efetiva potencialidade no contexto da aprendizagem. Não queremos com isso afirmar que o cinema representa a realidade ou pode substituir a história, mas que, para o senso comum, a linguagem cinematográfica produz um sentido narrativo de representações que mescla realidade e ficção, sem muito distanciamento.

Segundo Moscovici (1988), o senso comum é um tipo de pensamento em que as pessoas comuns procurariam articular o conhecimento à sua vida sem pretensão de transcendência e sem necessitar de regras e convenções para pensar. Seria um pensamento livre, embora fortemente influenciado pela tradição e pelos estereótipos de linguagem (MOSCOVICI; HEWSTONE, 1988).

O senso comum se mostra como uma forma de conhecimento efetivamente prático, elaborado a partir do imediatismo do cotidiano. Com esse caráter, a sua imagem como modelo de pensamento é despadronizada, porém não desestruturada. A estrutura sobre a qual se ergue o pensamento comum se caracteriza como estrutura informal, ou seja, uma espécie de estrutura (sociomental) semilógica e 
flexível, determinada pelo caráter espontâneo e prático por parte dos indivíduos no uso dos atos de fala e ações sociais no cotidiano.

O modus operandi da linguagem cinematográfica tem uma identificação com as formas simbólicas de representação, que facilitam a profusão discursiva que se almeja veicular. Assim, a linguagem cinematográfica atua como um instrumento de representação social imaginária que aproxima o distante, a ponto de juntar valores diferentes dentro de um mesmo discurso. A forma como o conjunto de representações sociais presente nos roteiros é objetivada na figuração da linguagem cinematográfica transforma o cotidiano em palco de ficção.

Essa relação de proximidade entre o cinema e a realidade facilita o trânsito das representações e, por extensão, a maior identificação com o seu dispositivo cultural. Muitos filmes têm essa facilidade de produzir aproximação entre realidade e ficção pelo aporte da reprodução de imagens cotidianas da vida social.

Pensamos na pertinência de utilizarmos esse caráter atributivo do cinema na escola, uma vez que a linguagem cinematográfica tem se afinado cada vez mais com os processos pedagógicos críticos nas reflexões sobre temas e problemas pertinentes à realidade concreta, que buscam instrumentos de emancipação de uma perspectiva crítica acerca do contexto social vivido. Quando empregado de forma crítica na escola, o cinema funciona como construtor de um conhecimento novo. Substituem-se, assim, os discursos "que se originam numa concepção de conhecimento que almeja a objetividade e têm a função de difundir conhecimento", por diálogos cuja meta "é a própria intersubjetividade" (DUARTE, 2010, p. 24).

Essa virada no papel que o cinema possa vir a desempenhar na produção do saber escolar está profundamente atrelada ao seu uso didático, onde este atua como uma "ferramenta na construção do saber" ou ainda como "campo de experimentação onde o conhecimento é vivenciado" (MAUAD, 2009, p. 247). Ao invés de assisti-lo como uma forma de mimetização da vida social, propomos uma "desorganização" escolar das imagens produzidas pelo cinema reificado, de modo que retomemos a capacidade de ver e pensar diante da crescente inflação de imagens. Considerando-se o caráter polissêmico das imagens, acreditamos que devem ser consideradas, em primeiro lugar, as múltiplas interpretações que podem ser geradas após o exercício de ver. Nesse sentido é importante o desenvolvimento de um processo de desnaturalização das imagens, estimulando uma subjetividade ativa em relação ao que é assistido (MAUAD, op. cit.).

Em segundo lugar, é relevante considerar ainda o desenvolvimento de um aprendizado cultural que favoreça a expansão de uma análise visual crítica dos filmes cinematográficos. Crítica no sentido de chamar a atenção para as significações culturais produzidas pelos filmes, as relações de poder aos quais estariam articulados e, finalmente, quais as práticas sociais que promovem e produzem. 
Esta análise visual crítica passa pelo conhecimento da gramática específica que envolve a produção cinematográfica, pelo exame dos efeitos de verdade que são produzidos através dos diálogos e do aparato cenográfico. Passa também pela reflexão sobre o contexto histórico de sua produção, pelo entendimento da diferenciação dos gêneros fílmicos e como estes contribuem para fixar os sentidos que se almeja passar.

Trata-se, portanto, de um exercício de desnaturalização que destitui o sentido inicial apresentado pelo filme e aponta para os sentidos subjacentes e potenciais existentes no mesmo filme; um esforço de examinar atentamente, primeiro, toda a materialidade do filme para que, a partir dos seus códigos internos, se torne possível compreender como esta materialidade interfere na construção de uma carga de significados e de sentidos.

Obviamente, não estamos propondo um "decifrar das imagens", mas ocupar-se em demonstrar, no espaço escolar, o caráter representacional das imagens produzidas pelo cinema. Ou seja: as imagens produzidas pelo cinema são imagens; não são verdades absolutas, embora se aproximem, através da apropriação de um sistema de significados próprios de uma determinada cultura, dos símbolos produzidos por esta mesma cultura.

Esse processo de desnaturalização do filme pode se realizar ainda através da utilização de filmes cujas temáticas exploram aspectos pouco abordados pelas redes discursivas estabelecidas. Este é o caso dos filmes produzidos por cineastas brasileiros a partir do final do século XX, especialmente a partir dos anos de 1960, cuja preocupação central tem sido dar visibilidade a grupos sociais que vivem em condições precárias, muitas vezes em condições desumanas, na sociedade brasileira, como Walter Salles em Central do Brasil; Hector Babenco com Carandiru e Lucio Flavio, passageiro da agonia; Sergio Machado, com Cidade baixa; Marcelo Masagão, com Nós que aqui estamos por vós esperamos, entre outros.

Para os interesses desse texto, vamos nos referir especificamente, a título de exemplo, à película Cidade de Deus (2002), dirigida pelo cineasta brasileiro Fernando Meirelles. Este optou por um roteiro cinematográfico que representa de forma positiva a vida cotidiana do cidadão comum vivente nas favelas cariocas e que se mostrou bastante convincente na representação social que integra ficção e realidade num mesmo conjunto discursivo.

A forma como o cinema de Meirelles apresenta a favela é bastante pedagógica, na medida em que o conjunto de valores apresentados como representações da realidade cotidiana reproduz os valores que a prática do senso comum assimila como possível dentro de seu conjunto de valores culturais. Parodiando o título da obra de Foucault (1992), Cidade de Deus é um exercício de exposição “Da vida dos homens infames", que ganham através da película uma notoriedade midiática. 
Propagam-se, através do filme, imagens não canônicas em sala de aula. Entendemos por imagens canônicas:

Aquelas imagens padrão ligadas a conceitos-chave de nossa vida social e intelectual. Tais imagens constituem pontos de referência inconscientes, sendo, portanto, decisivas em seus efeitos subliminares de identificação coletiva. São imagens de tal forma incorporadas em nosso imaginário coletivo que as identificamos rapidamente. (SALIBA, 2008, p. 88)

O fato do filme cinematográfico, isto é, um produto da cultura de massas, estar utilizando uma imagem não canônica não invalida o seu caráter de ruptura com imagens deterministas e estereotipadas. Esse caráter não canônico da representação do Brasil apresentada pelo filme de Meirelles pode acentuar o interesse pela imagem fílmica, ao mesmo tempo em que favorece a inserção de novos pontos de referência (SALIBA, op. cit.).

Mesclam-se na narrativa fílmica elementos da realidade social brasileira com aspectos característicos do microuniverso de um determinado grupo social, que vive numa espacialidade específica, ao mesmo tempo em que se coloca em exposição o cisma social em que vive a sociedade brasileira sem um apelo explícito para dualismos reducionistas: ricos e pobres, favela e asfalto.

Numa análise visual crítica acerca desse filme, Fischer (2008, p. 205) ressalta "as várias camadas de olhares que se sobrepõem e entrecruzam" no seu interior:

O olhar de Buscapé, intermediado pelo olho da máquina fotográfica, por sua vez mediado pelo olho da câmara de Meirelles (que olha a escrita de Paulo Lins), além do nosso olhar de espectadores. Todos esses olhares acabam por narrar aquelas histórias desafortunadas dos meninos e meninas da favela Cidade de Deus, reforçando a impossibilidade de dizer por completo que "isto é a favela Cidade de Deus", "isto é a violência e a pobreza no Brasil" e, ao mesmo tempo, reforçando a escolha de uma linguagem que busca exatamente afirmar: "isto é?".

Ao apontar para a impossibilidade de fixações de sentidos no filme, Fischer destaca o fato de que existem outras interpretações a serem exploradas e o fato inexorável de que se trata de uma representação da favela, apesar dos esforços do diretor em adotar uma linguagem, uma técnica e uma estética cinematográfica específicas para transformá-lo numa interpretação realística da vida na favela.

O caráter pedagógico presente no filme Cidade de Deus está na tentativa de passar uma relação de verossimilhança que minimiza a distância entre realidade e ficção. Sobre esse filme, podemos utilizar as palavras de Xavier (2003) quando aborda o cinema. Ele nos proporciona o usufruto de um olhar privilegiado sobre a favela, um olhar em que podemos estar lá sem efetivamente estarmos lá. O filme atua então como "um olho que não vejo e não me vê, que é olho porque substitui o 
meu, porque me conduz de bom grado ao seu lugar para eu enxergar mais... talvez menos" (p. 57).

Assim, o filme parece se apresentar como a soma das representações sociais possíveis da vida de uma comunidade de favela na cidade do Rio de Janeiro, tão repleta de inúmeras favelas, nas quais de alguma forma aqueles valores são reproduzidos como discurso de verdade. Tornam-se, portanto, instrumentos de alienação e desalienação da sociedade.

Abordando o exercício crítico dos filmes, Eduardo Morettin afirma:

[...] para que possamos recuperar o significado de uma obra cinematográfica, as questões que presidem seu exame devem emergir de sua própria análise. A indicação do que é relevante para a resposta de nossas questões em relação ao chamado contexto somente pode ser alcançada depois de feito o caminho acima citado, o que significa aceitar que todo e qualquer detalhe (do filme) [...] trata-se de desvendar os projetos ideológicos com os quais a obra dialoga e necessariamente trava contato, sem perder de vista sua singularidade dentro do seu contexto. (MORETTIN, 2003, p. 38)

Com tal proposição, os filmes cinematográficos, quando utilizados no espaço escolar, perdem o caráter meramente ilustrativo e/ou documental. Numa perspectiva objetivista, trata-se de destacar os efeitos de realidade gerados pela produção cinematográfica, mas sem perder de vista a sua natureza estética e polissêmica e os resultados advindos da experiência estética que é a fruição do filme.

Percebemos o filme como uma "pluralidade de canais" (XAVIER, citado por NAPOLITANO, 2008) e tomamos como ponto de partida para essa análise visual crítica as significações internas do próprio filme, buscando-se "os elementos narrativos que podem ser sintetizados na dupla pergunta: o que um filme diz e como o diz?" (NAPOLITANO, op. cit., p. 245).

Trata-se, pois, de um convite a refletir sobre o cinema para além do que ele se propõe a dizer ou mostrar, retirando o filme "do terreno das evidências" (SALIBA, 2008) e buscando nas suas formas decifrar aquilo que é fugidio e, por vezes, parece quase invisível aos nossos olhos; desestabilizando, desse modo, a ordem imagética que nos é apresentada; preenchendo os espaços brancos que são deixados para o gozo em massa, com um conteúdo crítico cujo prazer adviria dessa própria criticidade.

\section{Referências}

BENJAMIN, W. A obra de arte na era de sua reprodutibilidade técnica. In: BENJAMIN, W. Obras escolhidas. São Paulo: Brasiliense, 1984.

DUARTE, R. A pós-história de Flusser e a promessa do Brasil. In: CONGRESSO 
INTERNACIONAL DESLOCAMENTOS NA ARTE, 2010, Belo Horizonte. Anais... Belo Horizonte, 2010. Disponível em: <http://www.abrestetica.org.br/deslocamentos/ deslocamentos.pdf>. Acesso em: 18 dez. 2012.

FABRIS, E.H. Cinema e educação: um caminho metodológico. Educação E Realidade, Porto Alegre, v. 33, n. 1, p. 117-134, jan./jun. 2008.

FISCHER, R.M.B. Quando os meninos de Cidade de Deus nos olham. Educação $\mathcal{E}$ Realidade, Porto Alegre, v. 33, n. 1, p. 193-208, jan./jun. 2008.

FOUCAULT, M. O nascimento da clínica. Rio de Janeiro: Forense Universitária, 1980.

FOUCAULT, M. As palavras e as coisas: uma arqueologia das ciências humanas. São Paulo: Martins Fontes, 2000.

FLUSSER, V. Pós-história: vinte instantâneos e um modo de usar. São Paulo: Duas Cidades, 1983.

MACHADO, R. Foucault, filosofia e a literatura. Rio de Janeiro: Zahar, 2005.

MAUAD, A.M. Ver e conhecer: o uso de imagens na produção do saber histórico escolar. In: ROCHA, E.; MAGALHAES, M.; GONTIJO, R. (Org.). A escrita da história escolar: memória e historiografia. Rio de Janeiro: FGV, 2009.

MOSCOVICI, S. A representação social da psicanálise. Rio de Janeiro: Zahar, 1978.

MOSCOVICI, S.; HEWSTONE, M. De la ciencia al sentido común. In: MOSCOVICI, S. (Org.). Psicologia Social II. Barcelona: Paidós, 1988.

MORETTIN, E. O cinema como fonte histórica na obra de Marc Ferro. História, Questões e Debates, Curitiba, n. 20/38, p. 11-42, jan./jun. 2003.

NAPOLITANO, M. A História depois do papel. In: PINSKY, C. et al. (Org.). Fontes históricas. São Paulo: Contexto, 2008.

ROSE, G. Visual methodologies. London: Sage, 2001.

SALIBA, E.T. As imagens canônicas e a história. In: PINSKY, C. et al. (Org.). Fontes históricas. São Paulo: Contexto, 2008.

XAVIER, I. O olhar e a cena: melodrama, Hollywood, cinema novo - Nelson Rodrigues. São Paulo: Cosac \& Naify, 2003.

\section{Filmografia}

CIDADE Baixa. Direção: Sergio Machado. Produção: Walter Salles. Roteiro: Sergio Machado, Karim Ainouz. Intérpretes: Lazaro Ramos, Wagner Moura, Alice Braga e outros. Salvador: Lumiere, 2005. DVD (120 min). 
CIDADE de Deus. Direção: Fernando Meirelles. Produção: O2 Filmes, VideoFilmes, Andrea Barata Ribeiro e Mauricio Andrade Ramos. Roteiro: Braulio Montovani. Intérpretes: Matheus Nachtergaele, Leandro Firmino da Hora e outros. [S.1]: Lumiere, 2002. DVD (135 min).

NÓS que aqui estamos por vós esperamos. Direção, Produção e Roteiro: Marcelo Masagão. Documentário. Rio de Janeiro: Rio Filmes, 1999. DVD (73 min).

Recebido em 3 de janeiro de 2013.

Aprovado em 10 de setembro de 2013. 